\title{
Disparities in health care utilization among Latino children suffering from asthma in California
}

This article was published in the following Dove Press journal:

Pediatric Health, Medicine and Therapeutics

I I January 20 I I

Number of times this article has been viewed

\author{
Jongwha Chang ${ }^{*}$ \\ Isha Patel I* \\ Sherry T Liu ${ }^{2}$ \\ Alexander $\mathrm{N}$ Ortega ${ }^{3}$ \\ Jatin Srivastava ${ }^{4}$ \\ Yoon Shin Park ${ }^{5}$ \\ Sarah Kirk6 \\ Rajesh Balkrishnan ${ }^{1,7,8}$ \\ 'Department of Social and \\ Administrative Science, University \\ of Michigan, Ann Arbor, MI; ${ }^{2}$ College \\ of Public Health, The Ohio State \\ University, Columbus, $\mathrm{OH} ;{ }^{3} \mathrm{School}$ of \\ Public Health, University of California, \\ Los Angeles, CA; ${ }^{4}$ EW Scripps School \\ of Journalism, Ohio University, Athens, \\ $\mathrm{OH} ;{ }^{5}$ Department of Pharmaceutical \\ Science, University of Michigan, \\ Ann Arbor, MI; ${ }^{6}$ Texas Asthma Control \\ Program, Texas Department of State \\ Health Services, Austin, TX; ${ }^{7}$ Center \\ for Medication Use, Policy and \\ Economics, ${ }^{8}$ Department of Health \\ Management and Policy, University of \\ Michigan, Ann Arbor, MI, USA
}

*Both authors contributed equally to this project.

Correspondence: Jongwha Chang Department of Clinical, Social, and Administrative Science, University of Michigan, 428 Church St, Ann Arbor, MI 48I09, USA

Tel $+\mid 734936$ I505

Fax + I 734615 817|

Email jochang@umich.edu
Objectives: To examine any racial and ethnic differences in health care utilization among children with asthma by application of the Aday and Anderson's behavioral model of health care utilization.

Methods: The California Health Interview Survey (CHIS) is a noninstitutionalized household survey of California residents conducted biannually since 2001. Cross-sectional survey data were analyzed to identify differences by race and ethnicity among children with asthma. After adjusting for sample weights and design effects, children with asthma comprised a sample size of 400,000 in the 2007 CHIS database. Disparities in health care utilization across all racial and ethnic categories were analyzed using multivariate logistic regression analysis.

Results: Latino children with asthma were $49 \%$ more likely to have visited an emergency department in the previous year $(P<0.05)$ and $57 \%$ less likely to have visited a doctor $(P<0.05)$ compared with non-Latino children with asthma, after controlling for confounding variables. Furthermore, Puerto Rican children were $72 \%$ more likely to have visited an emergency department $(P<0.05)$ in the previous year and $38 \%$ less likely to have visited a doctor $(P<0.07)$ compared with non-Puerto Rican children.

Conclusion: This study provides evidence of disparities in health care utilization among Latino children overall as well as in Latino children belonging to different subgroups suffering from asthma. Examining factors leading to differences within the Latino subgroups could help to guide the tailoring of interventions and health care programs for children with asthma, thereby improving access to health care services for this underrepresented minority.

Keywords: racial disparities, Latino children, Puerto Ricans, Cuban Americans, CHIS, Mexican Americans, asthma

\section{Background}

Asthma, a chronic respiratory disease characterized by attacks of difficulty breathing, is one of the leading chronic childhood diseases in the US and a major cause of disability. ${ }^{1}$ Asthma not only limits a child's ability to engage in certain activities but also is associated with significant direct and indirect medical costs. Asthma emerged as an important public health issue during the 1980s, and its prevalence among children aged 0-17 years had more than doubled by 1996. Although there has been some stabilization in asthma prevalence rates in recent times, it still affected approximately 7 million $(9.3 \%)$ children in the US in $2008 .^{1}$

Various surveys conducted regionally and nationally indicate ethnic and racial disparities in asthma-related prevalence, diagnosis, morbidity, and mortality between Latinos and non-Latinos, as well as in the different Latino subgroups submit your manuscript $\mid$ www.dovepress.com

Dovepress

DOI: $10.2147 /$ PHMT.SI 5717
Pediatric Health, Medicine and Therapeutics 20I I:2 I-8

(C) 201 I Chang et al, publisher and licensee Dove Medical Press Ltd. This is an Open Access article which permits unrestricted noncommercial use, provided the original work is properly cited. 
(Mexican/Mexican American, Puerto Rican, Cuban/Cuban American or Dominican, and South/Central/Other Latin American). Studies have consistently shown asthma prevalence rates among Latino children to be higher than those in non-Latino Caucasian children. ${ }^{2-5}$ Looking further at the disparities within the Latino population, the studies have shown asthma to be generally more prevalent among Puerto Rican children than in non-Puerto Rican Latino children. In 2002, Cloutier et al reported that asthma prevalence rates among Puerto Rican children were 125\% higher than in non-Latino Caucasians, and $80 \%$ higher than in non-Latino African American children. ${ }^{6}$ Further exploring the impact of the disease in children, other studies have found that Puerto Rican children with asthma experience greater functional morbidity, missed more school days, and had more frequent exacerbations compared with other ethnic groups. ${ }^{6,7}$ Asthma mortality rates are also higher among Puerto Ricans than in other racial and ethnic groups. ${ }^{8}$ National and regional age-adjusted asthma-related mortality data collected by the National Center for Health Statistics (NCHS) in 19901995 revealed that the annual mortality rate was 40.9 per million for Puerto Ricans, followed by 38.1 per million for non-Latino African Americans, 15.8 per million for Cuban Americans, 14.7 per million for non-Latino Caucasians, and 9.2 per million for Mexican Americans. Similar mortality estimates were recorded among different Latino subgroups in 2004 as well. ${ }^{8,9}$ These disparities between different racial groups (eg, Caucasians, Latinos) and subgroups (eg, Puerto Ricans, Cubans, Mexicans) indicate a need to investigate possible contributing factors.

Studies exploring the factors contributing to this racial disparity show that lack of insurance, not having US citizenship, eligibility restrictions, administrative barriers, lack of documentation, parental confusion about eligibility for Medicaid or the State Children's Health Insurance Program, and fear of jeopardizing immigration status are associated with low access to health care among Latino children. ${ }^{8,10,11,12}$ Other factors, eg, lack of knowledge about asthma and how to address it, may also be obstacles to the effective management of childhood asthma. ${ }^{7}$ Medication intake behavior that might delay treatment efficacy might be influenced by cultural beliefs and norms about asthma and use of varied asthma management strategies by the family. ${ }^{13-15}$

The 1999 National Health Interview Survey (NHIS) analyzed ethnic and racial differences in asthma diagnosis in Latino children aged 3-17 years and, controlling for factors like gender, parental education, and place of residence, there was high reporting of wheezing among the Puerto
Rican subgroup of children. ${ }^{16}$ Since 2000, ambulatory care, which includes nonurgent physician and hospital outpatient department visits, has significantly increased despite relatively stable asthma prevalence. Physician visits account for the majority of ambulatory care visits for asthma. In 2004, 6.5 million visits for asthma occurred in physicians' offices compared with 0.5 million visits to hospital outpatient departments. Children in all the Latino subgroups (Mexican/ Mexican American, Puerto Rican, Cuban/Cuban American or Dominican, and South/Central/Other Latin American) had fewer physician visits compared with non-Latino Caucasian children. Also, Latino children who were not US citizens had a lower likelihood of physician visits compared with native or foreign-born Latino children with US citizenship. Puerto Ricans and other Latino subgroups had a higher likelihood of an emergency department visit compared with those of Mexican ancestry. ${ }^{17}$ Carr et al found that, after controlling for income, Latino and African American children had higher rates of hospitalization compared with non-Latino Caucasian children in many states. ${ }^{18}$

Data illustrate differences in the quality of care and treatment offered to Latinos. There is consistent evidence of racial and ethnic disparities in childhood asthma, especially among Latino subgroups such as Puerto Ricans. ${ }^{18}$ However, health care utilization among children belonging to the Latino subgroups remains understudied. While designing asthma interventions, combining these subgroups under the single umbrella of Latino ethnicity might obscure the underlying differences in asthma burden between the various Latino subgroups. ${ }^{16}$ This study seeks to identify differences in the utilization of health care services arising out of the impact of race/ethnicity among Latino and non-Latino children suffering from asthma. This study also investigates racial and ethnic differences in health care utilization in children with asthma who belong to different Latino subgroups.

\section{Materials and methods Data}

Data for this analysis were taken from the 2007 California Health Interview Survey (CHIS), conducted by the University of California at Los Angeles Center for Health Statistics. ${ }^{19}$ The survey comprised a household telephone interview that collected information in a cross-sectional manner on health, demographics, and socioeconomic status from noninstitutionalized people. A probability random digit dial sampling design was used to represent the state's population and featured an oversampled population of African Americans and Latinos in order to capture the racial and ethnic disparities 
among the minority populations. ${ }^{19}$ In 2007 , this survey collected a large amount of household, adult, and child data biannually from up to 53,000 households, including 12,526 children. The interviewers conducted the telephone survey in both the Spanish and English languages, thereby accommodating any cultural differences in health care utilization arising due to language barriers among Latinos. The overall screener response rate (ie, success in the process of introduction of the survey in the randomly selected household and random selection of an adult to complete the interview) was $35.5 \%$, and the overall adolescent response rate (ie, success in completing the extended interview with the randomly selected person) of completed extended interviews was $73.7 \%$. The data obtained from the extended interview completion process were used in the study. The response rates were consistent with those of general telephone surveys and similar to other recent major telephone health surveys conducted in California. ${ }^{20}$ In order to limit any concern that children might not be able answer the questions in the survey, the questions concerning the child were asked of an adult in the house, most often a parent/guardian or other family member acquainted with the health of the child.

According to the inclusion criteria, the study consisted of children aged $0-11$ years with a current diagnosis of asthma. The age range of $0-11$ years was selected because that was the only age range covered in the dataset. Children aged $0-11$ years who had been diagnosed with asthma were selected. Among those with a lifetime asthma diagnosis, only children identified as currently having asthma were included in the analysis. ${ }^{21}$

\section{Measures}

Differences in health care utilization were assessed by using two dependent variables. The first dependent variable was the number of emergency department visits made in the past year by the child and this was dichotomized into no emergency department visits and one or more emergency department visits. ${ }^{16}$ The second dependent variable measured the receipt of nonurgent care by the child, as defined by visits to health professionals, including physicians, nurse practitioners, or physician assistants in the past year. ${ }^{22}$

\section{Model}

Independent variables were selected from the multivariate framework based on Aday ${ }^{23,24}$ and Anderson's ${ }^{25}$ behavioral model of health care utilization. This model has been widely used to study health care-seeking behavior and determinants of health care utilization. The model focuses on understanding various characteristics associated with at-risk populations and populations suffering from chronic conditions. According to this model, there are predisposing, enabling, and needrelated factors. Predisposing factors determine the intent of an individual or a group leading to utilization of health care services. Enabling factors influence the patient's ability to access health care services. Need-related factors represent an individual's perception of his/her own health and the perception of the health care provider of the individual's health. ${ }^{23-25}$

Child race/ethnicity categories included non-Latino Caucasians, non-Latino African Americans, and other non-Latinos. Respondents identified as Latino were further divided into four subgroups, ie, Puerto Ricans, Cubans/Cuban Americans or Dominicans (Republic), Mexicans/Mexican Americans, and Central/South/Other Latin Americans. The remaining independent variables were possible covariates.

Predisposing factors included gender (female/male), mother's education (a high school degree or equivalent, college degree, and graduate or professional degree), and age (0-3, 4-6, 7-9, and 10-11 years). Need factor was measured by assessing child health status (poor, good, or excellent). Those characterized by poor health status were considered to have a high need for care, whereas those with a similar or an improved health status were considered to have a low need for care. Enabling factors were characterized as factors that affected the use of health care services, and included federal poverty level measured by family income, parental health insurance coverage, and use of an asthma management plan for the child. Income was categorized into families with a federal poverty level between $0 \%$ and $99 \%$, those with a federal poverty level between $100 \%$ and $299 \%$, and those

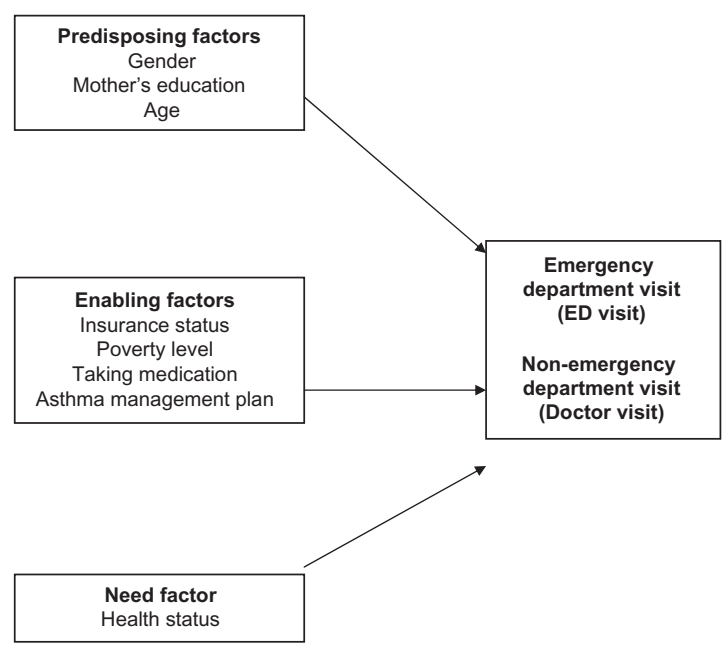

Figure I Aday-Anderson behavioral model for health care utilization. ${ }^{25}$ 
with a federal poverty level greater than 300\%. Parents who had any form of insurance like Medicare, Medicaid, private insurance, Indian Health Service, Veterans Affairs, other public insurance, other government insurance, or single insurance plans were classified as insured. The uninsured category included individuals that answered "none" to the question asking them about the type of insurance covered. ${ }^{8,19,26}$

\section{Statistical analysis}

The sample consisted of 1229 children with current asthma diagnosis aged 0-11 years and was classified under two categories, ie, ever been told they had asthma and still had asthma. Chi-squared tests were used to examine bivariate associations between the predictor variables and the use of emergency department care as well as between the predictor variables and the nonurgent care. The independent variables were listed under the categories of race/ethnicity, gender, age, child health status, maternal education, poverty level, parental health insurance coverage, use of an asthma management plan, and use of preventive medication in the past year.

Multivariate analyses were also conducted in order to examine the effects of race and Latino ethnicity on health care use among children with asthma, using separate logistic regression analyses and simultaneously controlling for enabling, predisposing, and need factors. Variables having significant $(P<0.05)$ bivariate associations with the dependent variables were included in the multivariate analyses. In addition, based on evidence from previous studies, ${ }^{10,11,16,18}$ variables associated with health care utilization in children suffering from asthma were also included in the multivariate analyses in order to control for any possible confounding in the study. All odds ratios (OR) and $P$ values were reported.

The full model was fitted into both the analyses. Initial analyses for both dependent variables (use of emergency department and nonurgent care) categorized ethnicity as Latino versus non-Latino. Subsequent analyses of both dependent variables used the four Latino subgroups.

Weighting was used in the CHIS dataset to measure collective statistics representative of the entire state. In particular, sample weighting compensated for differences in probabilities of sample selection and differences in the sampling rates of the households and persons interviewed. Weighting also reduced any bias arising from different characteristics of respondents and nonrespondents. Weighting reduced variance among the data collected, as well as compensating for undercoverage of the sample population while administering the survey. The sample weights used for statistical analysis in the study were created by CHIS. ${ }^{19}$
Although the model used variables from the child, adult, and family level, more emphasis was placed on the child-level survey. Therefore, weights from the child-level survey were used as recommended in the literature. ${ }^{22}$

\section{Results}

The descriptive statistics of the children suffering from asthma are listed in Table 1. Among the sample of 12,000 children obtained from the CHIS database, about 1029 children had been diagnosed with asthma once in their lifetime and also reported still having asthma. When the data for the children who still had asthma at the time of the survey were analyzed, weighted results showed that approximately $45.6 \%$ of Latino parents reported that the child visited the emergency department at least once. Also, about $16.7 \%$

Table I Weighted characteristics of ethnicity among children with asthma in California (values expressed as percentages)

\begin{tabular}{|c|c|c|c|}
\hline \multirow[t]{3}{*}{ Variables } & \multicolumn{2}{|c|}{ Ethnicity } & \multirow[t]{3}{*}{$P$ value' } \\
\hline & Latino & Non-Latino & \\
\hline & $n=618$ & $n=6 I I$ & \\
\hline \multicolumn{4}{|c|}{ Health care utilization in the past year } \\
\hline Had at least one doctor visit & 45.61 & $47.6 \mathrm{I}$ & $<0.01$ \\
\hline $\begin{array}{l}\text { Had at least one emergency } \\
\text { department visit }\end{array}$ & 16.71 & 12.24 & 0.12 \\
\hline Number of doctor visits & 50.36 & 49.64 & $<0.09$ \\
\hline \multicolumn{4}{|l|}{ Predisposing factors } \\
\hline Male & 49.79 & 53.58 & 0.41 \\
\hline Education & & & $<0.01$ \\
\hline High school graduate & 26.71 & 10.1 & \\
\hline College & 21.53 & 30.63 & \\
\hline Graduate school & 1.91 & 9.12 & \\
\hline Age (years) & & & 0.15 \\
\hline$\leq 3$ & 13.07 & 8.88 & \\
\hline $4-6$ & 10.91 & 12.43 & \\
\hline 7-9 & 15.20 & 16.80 & \\
\hline $10-11$ & 11.18 & 11.53 & \\
\hline \multicolumn{4}{|l|}{ Enabling factors } \\
\hline Health insurance & 48.37 & 48.34 & 0.28 \\
\hline Poverty level & & & $<0.01$ \\
\hline $0 \%-99 \%$ & 15.57 & 7.23 & \\
\hline $100 \%-299 \%$ & 21.56 & 13.69 & \\
\hline$\geq 300 \%$ & 13.23 & 28.72 & \\
\hline Taking medication for asthma & 16.49 & 13.23 & 0.13 \\
\hline $\begin{array}{l}\text { Asthma management plan } \\
\text { for child }\end{array}$ & 24.70 & 23.33 & 0.64 \\
\hline \multicolumn{4}{|l|}{ Need factors } \\
\hline Self-reported health status & & & $<0.01$ \\
\hline Excellent & 27.13 & 32.82 & \\
\hline Good & 15.47 & 13.35 & \\
\hline Poor & 7.76 & 3.46 & \\
\hline
\end{tabular}

Notes: Date source: California Health Interview Survey (CHIS) 2007. ' $P$ values are based on Chi-square test for categoric variables and Student's $t$-test for continuous variables (linearized standard error is in parentheses) comparing Latino and non-Latino children residing in California (aged $\leq$ II years). 
of Latino parents reported using nonurgent care for their children. Most of the parents reported that their child/children were in comparatively good or excellent health as opposed to the previous year. The majority of children in the sample had parents who were insured and had a federal poverty level between $0 \%$ and $99 \%$ per year. In the children with asthma, although $75 \%$ of the children did not use an asthma management plan, nearly $16.5 \%$ used preventive medications. A lower rate of health care utilization was evident from the fact that Latino children were significantly less likely to report at least one doctor visit in the previous year compared with non-Latino children $(P<0.01)$. In contrast, differences in emergency department utilization were not statistically significant between Latino and non-Latino children. Dissimilarities between the Latino and non-Latino children $(P<0.01)$ may also persist because of the notably significant self-reported differences between education and poverty level. Several variables were not significantly associated with
Latino subgroups in the multivariate model presented in this study, but they were still included in the multivariate model because they were found to be significant predictors in some of the previous studies cited in the literature. ${ }^{8,15,17}$

Logistic regression was conducted and its results are shown in Table 2. Non-Latino children were categorized as the reference group. After controlling for potential confounding variables, Latino children with asthma still had a higher risk $(\mathrm{OR}=1.49$, confidence interval $[\mathrm{CI}]$ 1.43-1.54) for an emergency department visit and a lower risk $(\mathrm{OR}=0.43$, CI 0.18-0.98) for a doctor visit. After controlling for independent variables, Puerto Rican children with asthma were $72 \%$ $(\mathrm{OR}=1.72$, CI 1.09-2.32) more likely to have at least one emergency department visit and $38 \%(\mathrm{OR}=0.62$, CI 0.32 ,0.93 ) less likely to have at least one doctor visit compared with other Latino subgroups. Children with asthma and at a poverty level of $100 \%-299 \%$ and $\geq 300 \%$ comprised $52 \%$ and $55 \%$ of the sample, respectively, and were less likely to

Table 2 Multivariate analyses (weighted)

\begin{tabular}{|c|c|c|c|c|c|c|c|c|}
\hline \multirow{3}{*}{$\begin{array}{l}\text { Variables } \\
\text { Latino versus non-Latino }\end{array}$} & \multicolumn{8}{|c|}{ Logistic estimation (odds ratio) } \\
\hline & \multicolumn{2}{|c|}{$\begin{array}{l}\text { Emergency } \\
\text { department visit }^{\prime}\end{array}$} & \multicolumn{2}{|c|}{$\begin{array}{l}\text { Emergency } \\
\text { department visit' }\end{array}$} & \multicolumn{2}{|c|}{ Doctor visit ${ }^{2}$} & \multicolumn{2}{|c|}{ Doctor visits $^{2}$} \\
\hline & 1.49 & $* *$ & & & 0.43 & ** & & \\
\hline Latino subpopulations (Puerto & & & 1.72 & $* *$ & & & 0.62 & $*$ \\
\hline \multicolumn{9}{|l|}{ Rican versus non-Puerto Rican) } \\
\hline \multicolumn{9}{|l|}{ Predisposing factors } \\
\hline Male & 0.92 & & 0.88 & & 1.40 & & 1.17 & \\
\hline \multicolumn{9}{|l|}{ Mother's education } \\
\hline High school graduate & - & & - & & - & & - & \\
\hline College & 1.25 & & $\mathrm{I} .25$ & & 3.78 & $* *$ & 3.54 & $* * *$ \\
\hline Graduate school & 0.68 & & 0.66 & & 5.95 & $* *$ & 5.44 & $* *$ \\
\hline \multicolumn{9}{|l|}{ Age (years) } \\
\hline$\leq 3$ & - & & - & & - & & - & \\
\hline $4-6$ & 0.33 & $* * *$ & 0.30 & $* * *$ & 3.27 & $*$ & 2.53 & \\
\hline 7-9 & 0.27 & $* * *$ & 0.25 & $* * *$ & 1.23 & & 0.93 & \\
\hline $\mid 0-11$ & 0.35 & $* * *$ & 0.36 & $* * *$ & 0.54 & & 0.36 & \\
\hline \multicolumn{9}{|l|}{ Enabling factors } \\
\hline Health insurance & 1.27 & & 1.26 & & 1.38 & & 1.27 & \\
\hline \multicolumn{9}{|l|}{ Poverty level } \\
\hline $0 \%-99 \%$ & - & & - & & - & & - & \\
\hline $100-299 \%$ & 0.48 & $*$ & 0.55 & $*$ & 0.21 & ** & 0.26 & $* *$ \\
\hline$\geq 300 \%$ & 0.45 & $*$ & 0.44 & $* *$ & 0.27 & ** & 0.33 & $*$ \\
\hline Taking medication for asthma & 1.65 & $*$ & 1.59 & $*$ & 1.12 & & 1.21 & \\
\hline Asthma management plan for child & 1.57 & $*$ & 1.36 & & 1.88 & & 2.17 & $*$ \\
\hline \multicolumn{9}{|l|}{ Need factors } \\
\hline \multicolumn{9}{|l|}{ Self-reported health status } \\
\hline Poor & - & & - & & - & & - & \\
\hline Good & 0.79 & & 0.77 & & 2.59 & & 2.28 & \\
\hline Excellent & 0.51 & & 0.48 & $*$ & $\mathrm{I} .43$ & & 1.22 & \\
\hline Constant & - & & - & & - & & - & \\
\hline
\end{tabular}

Notes: *Significant at the $10 \%$ level; **Significant at the $5 \%$ level; ***Significant at the $1 \%$ level. 'had at least one doctor visit in the past year; ${ }^{2}$ had at least one emergency department visit in the past year. 
have at least one emergency department visit compared with children with asthma and a poverty level of $0 \%-99 \%$.

\section{Discussion}

Analysis of the 2007 CHIS data revealed racial/ethnic differences in the utilization of emergency department and nonurgent care among children with asthma. Latino children suffering from asthma were $49 \%$ more likely to have at least one visit to the emergency department compared with $39 \%$ $(16.71 \%+12.24 \%$ in Table 1$)$ of all children with asthma. Equally disconcerting was the finding that although $92 \%$ $(45.61 \%+47.61 \%$ in Table 1$)$ of all children with asthma reported using nonurgent care in the past year, Latinos were $57 \%$ less likely to have used such care in the same time frame. Similar differences can be seen among Latino subgroups as well. Puerto Rican children with asthma were $72 \%$ more likely to have at least one emergency department visit in the past year and 38\% less likely to use nonurgent care in the past year, respectively, compared with other Latino subgroup children suffering from asthma. Overall, more use of emergency departments and less use of nonurgent care were seen in the Latino children, especially in the Puerto Rican subgroup, who are disproportionately affected by asthma, which could have important policy implications. Studies have shown that regular visits to the primary care physician are more cost-effective than visiting the emergency department. Also, primary care physicians provide comprehensive and continuous care, mostly of a preventive nature, in a better fashion than emergency department physicians, and in accordance with the child's medical history, response to previous treatments, and medication compliance. In turn, this saves patients and the entity providing insurance the extra cost of care provided in the emergency department. ${ }^{27,28}$ Differences in health care utilization among the Latino subgroups might stem from factors that could not be captured by this study.

One of the reasons for reduced use of nonurgent care among Latinos might be their limited English proficiency. Derose and Baker have shown that limited English proficiency among Latinos affects the number of physician visits they make. ${ }^{29}$ Poor English proficiency is also associated with poor health and the absence of insurance of any type or any regular source of care. ${ }^{29}$ For these patients, physicians and health care providers can undertake measures like avoiding complicated medical terms, providing instructions in simple language, asking the patient to repeat the instructions given for administering the medication, and distribution of low-literacy asthma educational materials to the patients. ${ }^{30}$ Also, patient-provider language barriers can be reduced by improving workforce diversity, implementing culturally competent staff, and providing communication skills training to the staff. ${ }^{30}$

The fact that health care utilization by children is largely determined by their parents cannot be ignored. Studies have shown that Latino adults who are immigrants with US citizenship and legal authorization demonstrate less fear while assessing health care services and also make more use of health care services. . $^{17,31,32}$

The differences in smoking behavior seen among the different Latino subgroups might lead to variations in the asthma risk seen in their children. The smoking habit is pronounced among Puerto Rican women aged 12-49 years, $32 \%$ of whom smoke, compared with $23 \%$ of Cuban American women and 21\% of Mexican American women. The secondhand smoke that the child is exposed to or from the mother smoking during pregnancy, which might affect the intrauterine development of the child, might be further factors contributing to asthma risk in these children. Health care providers can thus recommend counseling and smoking cessation programs to the parents of such children. ${ }^{30,33}$

Disparities in family structure and cultural values can be seen among the different Latino subgroups, eg, the concept of "familismo" comprising intact family structures, social support, and protective social factors, including the presence of two-parent households as seen among Mexican Americans compared with single-parent households as seen in mainland Puerto Ricans. Also, emphasis is placed on higher education among Cuban Americans. All these factors might explain the coping mechanisms required to meet the demands of children with chronic conditions. ${ }^{33}$

The interventions designed for targeting asthma should be based on data that are updated and comprehensive in order to provide access to culturally relevant health care services in a timely fashion at both the regional and national level. ${ }^{35}$ The good news is that as a result of the Healthy People 2010 guidelines, measures that improve data collection on asthma and asthma monitoring were included in the 2007 CHIS database and will be available to track trends and hopefully improvements. In order to reduce disparities, culturally sensitive community-based outreach programs should be designed that educate people about the use of preventive asthma medications and asthma management plans. Asthma management plans must include the updated guidelines recommended for asthma control. School-based interventions, written asthma action plans, and case management should be promoted as per the needs of the community. Parents should be educated about better living conditions, 
thereby minimizing the exposure of environmental triggers in schools, workplaces, and homes, in order to reduce the frequency of asthma attacks among the children. These outreach programs might help improve the access, quality, and demand of health care among the poor and uninsured racial and ethnic groups who disproportionately bear the burden of asthma, especially the Puerto Ricans. ${ }^{33,34}$

Although the study provides important data, it has some limitations. First, the data were reported by an adult who is knowledgeable about the child's health status, and there remains a potential for recall bias. Second, the sampling design of CHIS did not make it possible to calculate estimates smaller than the regional level. The information about the kind of kinship between the parent and child was not captured in this study. The survey did not capture details about the level of knowledge possessed by the parents about the quality of care and treatment received by their children for asthma. Our study also does not capture the legal status of Latino children suffering from asthma. A recent study by Esteban et al showed that the differences in asthma morbidity and use of emergency departments were marked among migrant Latinos and US-born Latinos. ${ }^{35}$ It is possible that the Latino paradox might exist in this population because California has a large immigrant population. ${ }^{36}$ The data collected in the study were self-reported, which had certain limitations. Selfreported data might not present an accurate level of need if they exclude a portion of the population with impaired access to care. Despite all these limitations, self-reported data have external validity and are more generalizable because they are representative of diverse patient populations. The CHIS was an appropriate choice because California has the nation's largest Latino population, which amounts to about 13.1 million people, according to the US Census Bureau..$^{36,37,38}$ Also, CHIS oversampled African Americans and Latinos. This ensured a large sample size, which might improve the generalizability of our results. On the other hand, comparable survey studies should be conducted in the states of Texas, Florida, Illinois, and New Mexico, which also hold a considerable population of Latinos, to study further the disparities among the different Latino subgroups, if any. Future studies looking at disparities among the Latino subgroups will help to focus on their distinct needs as well as help in tailoring specific interventions.

\section{Conclusion}

The results of this study provide useful information about the current utilization of health care among Latino children with asthma. Furthermore, this study highlights the importance of examining differences within the Latino subgroups, which can guide the tailoring of interventions and health care programs for children with asthma. Overall, this might be a small step toward a better understanding of the factors that serve as barriers to health care access among Latino children, who are an underrepresented minority population.

\section{Disclosure}

The authors report no conflicts of interest in this work.

\section{References}

1. US Department of Health and Human Services, Centers for Disease Control and Prevention, National Center for Health Statistics. Summary Health Statistics for US Children: National Health Interview Survey, 2008. Available at: http://www.cdc.gov/nchs/data/series/sr_10/sr10_244. pdf. Accessed November 23, 2010.

2. Carter-Pokras OD, Gergen PJ. Reported asthma among Puerto Rican, Mexican-American, and Cuban children, 1982 through 1984. Am J Public Health. 1993;83:580-582.

3. Ledogar RJ, Penchaszadeh A, Garden CC, et al. Asthma and Latino cultures: Different prevalence reported among groups sharing the same environment. Am J Public Health. 2000;90:929-935.

4. Lara M, Lara A, Flores G, et al. Heterogeneity of childhood asthma among Hispanic children: Puerto Rican children bear a disproportionate burden. Pediatrics. 2006;117:43-53.

5. Davis AM, Kreutzer R, Lipsett M, et al. Asthma prevalence in Hispanic and Asian American ethnic subgroups: results from the California Healthy Kids Survey. Pediatrics. 2006;118;e363-e370.

6. Cloutier MM, Wakefield DB, Hall CB, et al. Childhood asthma in an urban community: prevalence, care system and treatment. Chest. 2002; 122:1571-1579.

7. Findley S, Lawler K, Bindra M, et al. Elevated asthma and indoor environmental exposures among Puerto Rican children of East Harlem. J Asthma. 2003;40:557-569.

8. Canino G, Koinis-Mitchell D, Ortega AN, et al. Asthma disparities in the prevalence, morbidity, and treatment of Latino children. Soc Sci Med. 2006;63:2926-2937.

9. Homa DM, Mannino DM, Lara M. Asthma mortality in US Hispanics of Mexican, Puerto Rican, and Cuban heritage, 1990-1995. Am J Respir Crit Care Med. 2000;161:504-509.

10. Kaushal N, Kaestner R. Welfare reform and health insurance of immigrants. Health Serv Res. 2005;40:697-721.

11. Zuvekas SH, Taliaferro GS. Pathways to access: Health insurance, the health care delivery system, and racial/ethnic disparities, 1996-1999. Health Aff (Millwood). 2003;22:139-153.

12. Smedley BD, Stith AY, Nelson AR, editors. Unequal treatment: Confronting Racial and Ethnic Disparities in Health Care. Committee on Understanding and Eliminating Racial and Ethnic Disparities in Health Care. Washington, DC: National Academy Press; 2002.

13. Guarnaccia PJ, Pelto PJ, Schensul SL. Family health culture, ethnicity, and asthma: coping with illness. Med Anthropol. 1985;9:203-224.

14. Bearison DJ, Minian N, Granowetter L. Medical management of asthma and folk medicine in a Hispanic community. J Pediatr Psychol. 2002; 27:385-392.

15. Pachter LM, Cloutier MM, Bernstein BA. Ethnomedical (folk) remedies for childhood asthma in a mainland Puerto Rican community. Arch Pediatr Adolesc Med. 1995;149:982-988.

16. Akinbami LJ, Rhodes JC, Lara M. Racial and ethnic differences in asthma diagnosis among children who wheeze. Pediatrics. 2005;115: $1254-1260$.

17. Perez VH, Fang H, Inkelas M, et al. Access to and utilization of health care by subgroups of Latino children. Med Care. 2009;47:695-699. 
18. Carr W, Zeiter L, Weiss K. Variations in asthma hospitalizations and deaths in New York City. Am J Public Health. 1992;81:59-65.

19. California Health Interview Survey (CHIS) 2007. Area probability sample to access nonresponse bias; 2008.

20. Leeter $\mathrm{S}$. The impact of cell phone noncoverage bias on polling in the 2004 presidential election. Public Opin Q. 2006;70:88-98.

21. National Institutes of Health. National Heart, Lung, and Blood Institute. National Asthma Education and Prevention Program. Guidelines for the Diagnosis and Management of Asthma - Update on Selected Topics 2007. Available at: http://www.nhlbi.nih.gov/guidelines/asthma/ asthgdln.htm. Accessed November 23, 2010.

22. Vargas BA, Fang, H, Rizzo, JA, et al. Understanding observed and unobserved health care access and utilization disparities among US Latino adults. Med Care Res Rev. 2009;66:561-577.

23. Aday LA. Health status of vulnerable populations. Annu Rev Public Health. 1994;15:487-509.

24. Aday LA. At Risk in America: the Health and Health Care Needs of Vulnerable Populations in the US. San Francisco, CA: Jossey-Bass Publishers; 1993.

25. Anderson R. Revisiting the behavior model and access to care: does it matter? J Health Soc Behav. 1995;36:1-10.

26. Estrada AL, Treviño FM, Ray LA. Health care utilization barriers among Mexican Americans: evidence from HHANES 1982-1984. Am J Public Health. 1990;80 Suppl:27-31.

27. Phelps K, Taylor C, Kimmel S, et al. Factors associated with emergency department utilization for nonurgent pediatric problems. Arch Fam Med. 2000;9:1086-1092.

28. Halfon N, Newacheck PW, Wood DL, St. Peter RF. Routine emergency department use for sick care by children in the US. Pediatrics. 1996; 98:28-34.
29. Derose KP, Baker DW. Limited English proficiency and Latinos' use of physician services. Med Care Res Rev. 2000;57:76-91.

30. Canino G, McQuaid EL, Rand CS. Addressing asthma health disparities: A multilevel challenge. J Allergy Clin Immunol. 2009;123: 1209-1217.

31. Ortega AN, Fang H, Perez VH, et al. Health care access, use of services, and experiences among undocumented Mexicans and other Latinos. Arch Intern Med. 2007;167:2354 -2360.

32. Berk ML, Schur CL. The effect of fear on access to care among undocumented Latino immigrants. J Immigr Health. 2001;3: 151-156.

33. Lara M, Morgenstern H, Duan N, et al. Elevated asthma morbidity In Puerto Rican children: A review of possible risk and prognostic factors. West J Med. 1999;170:75-84.

34. Meng Y, Babey S, Alcolm E, et al. Asthma in California: finding from the 2001 California Health Interview Survey. Los Angeles, CA: UCLA Center for Health Policy Research; 2003.

35. Esteban CA, Klein RB, McQuaid EL, et al. Conundrums in childhood asthma severity, control, and health care use: Puerto Rico versus Rhode Island. J Allergy Clin Immunol. 2009;124:238-244.

36. Abraído-Lanza AF, Dohrenwend BP, Ng-Mak DS, Turner JB. The Latino mortality paradox: a test of the "salmon bias" and healthy migrant hypotheses. Am J Public Health. 1999;10:1543-1548.

37. US Census Bureau. The 2010 Statistical Abstract - The National Data Book. Resident Population by Race, Hispanic Origin, and Single Years Of Age: 2008. Available at: http://www.census.gov/compendia/statab/ cats/population.html. Accessed November 23, 2010.

38. US Census Bureau. Hispanic Population of the US. Available at: http://www.census.gov/population/www/socdemo/Hispanic. Accessed November 23, 2010.
Pediatric Health, Medicine and Therapeutics

\section{Publish your work in this journal}

Pediatric Health, Medicine and Therapeutics international, peerreviewed, open access journal publishing original research, reports, editorials, reviews and commentaries. All aspects of health maintenance, preventative measures and disease treatment interventions are addressed within the journal. Practitioners from all disciplines

\section{Dovepress}

are invited to submit their work as well as healthcare researchers and patient support groups. The manuscript management system is completely online and includes a very quick and fair peer-review system. Visit <http://www.dovepress.com/testimonials.php $>$ to read real quotes from published authors. 